\title{
Application of energy storage devices in power systems
}

\author{
Ravi Gupta, N K Sharma, P Tiwari*, Astha Gupta, Nitisha Nigam, Anubha Gupta \\ Department of Electrical and Electronics Engineering, Krishna Institute of Engineering and Technology, INDIA \\ ${ }^{*}$ Corresponding Author: e-mail: tiwari_p@kiet.edu, Tel +919759352541, Fax.+91-120-2675091
}

\begin{abstract}
In Electric Power systems, power quality has been one of the issues of increasing interests. Energy storage does not mean just the energy sources but they also provide the added benefits of improving power quality, dynamic and transient stability and also the reliability of the supply. Some of the major disadvantages in electric power supply system have been flickering and deviations in power supply which make some of the electronic equipments and domestic devices highly sensitive to it. To avoid such problems we need to find out devices that can provide a backup during the time of voltage sags and such deviations. The paper concentrates on performance benefits of adding energy storage to power electronic compensators for utility applications. The paper concerns on analysis of various energy storage devices on the basis of different parameters out of which Superconducting magnetic energy storage technology and Super capacitor energy storage has become an alternative for conventional solutions with negligible losses. Flywheel is used for non polluting uninterruptible power supply. For large scale storage, Underground thermal, Compressed air and Pumped hydrogen are preferred but it is difficult to compare all these devices as none of them are optimal for all applications.
\end{abstract}

Keywords: Battery Storage, Compressed Air Energy Storage, Flywheels, PHESS, SMES, SCES

\section{Introduction}

The production of electric energy is basic pillar for normal functioning of every modern society. The consumers' demand for electric power varies cyclically during day and night, as well as within the week and the seasons. The quality of an electric power supply is determined by the available reserve capacity at the energy utility. The distribution of electric-systems capacity is expressed by a typical weekly load curve of an electric utility. The power system should have $15-20 \%$ of reserve power available to be able to meet any customer demand (Yurek, 1999). If there is no or insufficient reserve capacity and the load level exceeds the power generation level, a decline in voltage at the consumer side will appear which would upset the normal operation of the users' machines and electrical devices or even cause them to fail. For this reason it is essential for the normal functioning and development of each social community to have reliable national and local electric power systems with capacities exceeding the actual energy demand by at least $15 \%$ according to work done by Yurek (1999). Unfortunately, however, only rich and advanced modern countries possess such high-grade energy systems. The power systems of most countries in the world have capacities that only just meet their energy demands, and in some cases are simply inadequate. This hunger for electricity is very often a limiting factor for the economic and social development of a country. The electric energy needs of the population, industry, agriculture, transport, etc. increase every year, and the claims for high-quality electric power become ever more demanding in relation to the increasing automation and computerization of the national economy.

\section{Types of Energy Storage Systems}

Electrical energy in an ac system cannot be stored electrically. However, energy can be stored by converting the ac electricity and storing it electromagnetically, electrochemically, kinetically, or as potential energy. Each energy storage technology usually includes a power conversion unit to convert the energy from one form to another. 
It has been established that the different forms of motion e.g. mechanical, thermal, electromagnetic, gravitational, chemical, etc. are converted into one another following definite quantitative ratio. To allow measurement of the various forms of motion by a unified measuring unit, the term energy has been introduced. The electrical energy is determined from the product of the voltage and the quantity of charge that passes through an electrical device (load). The work done per unit time is called power. Electrical power is determined from the product of voltage and current. In an electrochemical power source, a battery in particular, this energy transformation path is much shorter. In this case, through electrochemical reactions of oxidation and reduction proceeding on the surface of the two electrodes, the chemical energy is directly transformed into electrical power. Conversion of one type of energy into another requires a certain time period. The time needed for an energy-generating system to change its power from a value to another value is called response time.

\subsection{Superconducting Magnetic Energy Storage (SMES):}

This is an energy storage device with a lot of promise in effectiveness in terms of capacity and efficiency. Operation and control of this device may be divided in to two parts as follows:

2.1.1 Operation: An SMES unit is a device that stores energy in the magnetic field generated by the dc current flowing through a superconducting coil. An SMES unit consists of a large superconducting coil at the cryogenic temperature. This temperature is maintained by a cryostat or Dewar that contains helium or nitrogen liquid vessels. A power conversion/conditioning system (PCS) connects the SMES unit to an ac power system, and it is used to charge/discharge the coil. Two types of power conversion systems are commonly used. One option uses a current source converter (CSC) to both interface to the ac system and charge/discharge the coil. The second option uses a voltage source converter (VSC) to interface to the ac system and a dc-dc chopper to charge/discharge the coil. The VSC and dc-dc chopper share a common dc bus. The modes of charge/discharge/standby are obtained by controlling the voltage across the SMES coil. The SMES coil is charged or discharged by applying a positive or negative voltage across the superconducting coil. The inductively stored energy ( in joules) and the rated power (in watts) are the given specifications for SMES devices, and they can be expressed as follows:

$$
\begin{aligned}
& E=\frac{1}{2} L I^{2} \\
& P=\frac{d E}{d T}=L I \frac{d I}{d T}
\end{aligned}
$$

Where $\mathrm{L}$ is the inductance of the coil, I is the dc current flowing through the coil, and V is the voltage across the coil. Since energy is stored as circulating current, energy can be drawn from an SMES unit with almost instantaneous response with energy stored or delivered over periods ranging from a fraction of a second to several hours.

The modes of charge/discharge/standby are obtained by controlling the voltage across the SMES coil ( $\left.\mathrm{V}_{\text {COIL }}\right)$. The SMES coil is charged or discharged by applying a positive or negative voltage, $\left(\mathrm{V}_{\mathrm{COIL}}\right)$, across the superconducting coil. The SMES system enters a standby mode operation when the average $\mathrm{V}_{\text {COIL }}$ is zero, resulting in a constant average coil Current $\mathrm{I}_{\text {COIL }}$ shown in the figure above. The solenoid type (as shown in Figure 1) has been used widely due to its simplicity and cost effectiveness.

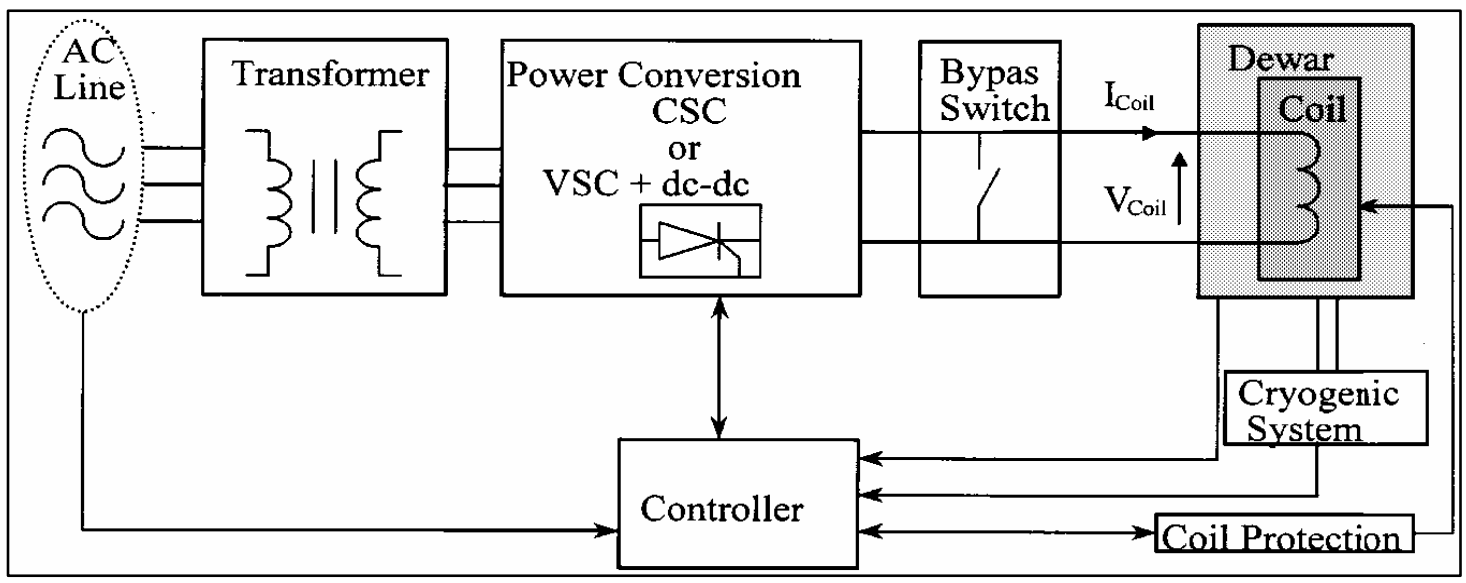

Figure 1. Components of SMES 
2.1.2 Performance Characteristics: SMES' efficiency and fast response capability (MW/millisecond) have been, and can be further exploited in applications at all levels of electric power systems. Some of them are:

- Frequency support (spinning reserve) during loss of generation.

- Enhancing transient and dynamic stability.

- Dynamic voltage support (VAR compensation).

- Improving power quality.

- Increasing transmission line capacity, thus enhancing overall security and reliability of power systems.

- It has efficiency greater than or equal to $90 \%$.

Further development continues in power conversion systems and control schemes, evaluation of design and cost factors, and analysis for various SMES system applications. Its characteristics are better described by Figure 2 .

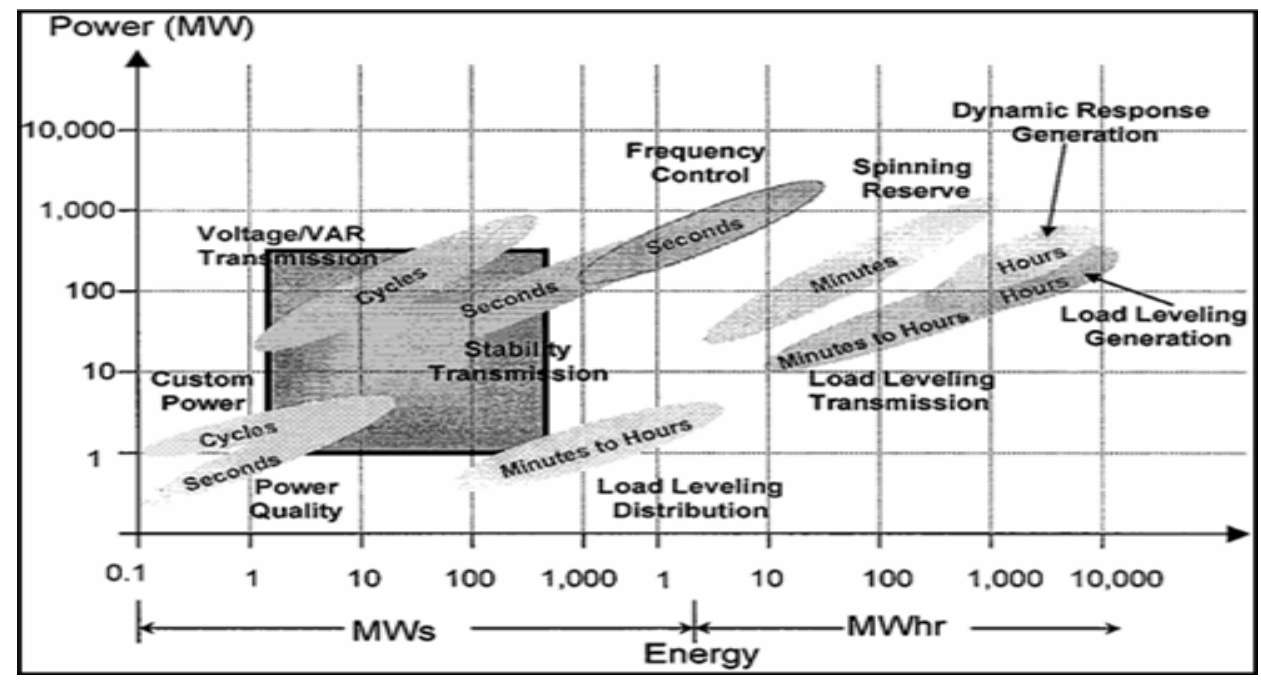

Figure 2. Energy-power characteristics of SMES applications taken from Buckles (2000)

The dynamic performance of a SMES system is far superior to other storage technologies. Faster and more efficient access to the stored energy and a shorter response time are the leading advantages. But there are a few concerns in it application at large scale. One of the major problems is its price. When compared with other energy storage technologies, today's SMES systems are still costly. However, the integration of an SMES coil into existing FACTS devices eliminates the cost for the inverter unit, which is typically the largest portion of the cost for the entire SMES system. The use of high temperature superconductors should also make SMES cost effective due to reductions in refrigeration needs. There are a number of ongoing SMES projects currently throughout the world.

\subsection{Super Capacitor Energy Storage (SCES):}

Super Capacitors are double layer capacitors that increase energy storage capability due to a large increase in surface area through use of a porous electrolyte (they still have relatively low permittivity and voltage-withstand capabilities). Direct storage of electrical energy is also possible by using super capacitors (SC). The energy is stored in the electric field of the capacitor by applying a DC voltage across the electrodes of the SC. The appropriate power converter and charging discharging switch are necessary. SC's never needs replacing because unlike batteries, they do not undergo life-limiting, irreversible, chemical reactions, and unlike Al-electrolytic capacitors, they do not experience dry-up problems. SC's, also known as Double Layer Capacitors, are a new electric energy storage device with extremely high capacity density and more (typical capacitors reaches hardly $40 \mathrm{pF} / \mathrm{cm}^{2}$ ). They have a virtually unlimited service life, fast charge discharge capability and very low leakage current.

SC's have also the possibility to be built in a modular way (a number of SC's in series). A comparison between batteries and SC can easily be made. A rechargeable battery weights more than double of a SC of the same size because battery stores energy by chemical reactions, it will generally take much longer to recharge. SC can be charged for $60 \%$ to $80 \%$ in just 30 to $60 \mathrm{~s}$. Rechargeable batteries have about 500 to 1000 life cycles as explained by Bullard (1989). On the other hand, SC can undergo charging discharging cycles for more than 1 million times without any reduction of its energy storage capacity. Incorrect installation, causing reverse voltage, will not damage the Super Capacitor where as a battery will be destroyed within minute. The use of SC in conjunction with batteries has a lot of advantages. In this way, a SC covers the gap between the maximum capacitive value of a traditional capacitor and the value of a battery. Therefore, SC can be recommended when storage devices are sought including all positive characteristics of a battery and a capacitor in a single device. 
2.2.1 Operation: Capacitors store electric energy by accumulating positive and negative charges (often on parallel plates) separated by an insulating dielectric. The capacitance represents the relationship between the stored charge, and the voltage between the plates. The energy stored on the capacitor depends on the capacitance and on the square of the voltage.

$$
E=\frac{1}{2} C V^{2}
$$

The amount of energy a capacitor is capable of storing can be increased by either increasing the capacitance or the voltage stored on the capacitor. The stored voltage is limited by the voltage-withstand-strength of the dielectric (which impacts the distance between the plates.

2.2.2 Performance Specification: The Performance Specifications of Super capacitors can be specified as follows:

- Capacitors are used in many ac and dc applications in power systems. DC storage capacitors can be used for energy storage for power applications.

- However, the present generation of dc storage capacitors finds limited use as large-scale energy storage devices for power systems. Capacitors are often used for very short-term storage in power converters. Additional capacitance can be added to the dc bus of motor drives and consumer electronics to provide added ability to ride voltage sags and momentary interruptions.

- The main transmission or distribution system application where conventional dc capacitors are used as large-scale energy storage is in the distribution dynamic voltage restorer (DVR), a custom power device that compensates for temporary voltage sags on distribution systems. The power converter in the DVR injects sufficient voltage to compensate for the voltage sag.

- The capacity density is more than twenty times larger than those of conventional capacitors and a stable operating performance throughout a large temperature range is guaranteed. One of the biggest advantages is the high volumetric energy density of a SC; the EM is 10 to 100 times larger than that of conventional capacitors. Due to the use of aqueous and non aqueous electrolytes, charging voltages of $1.2 \mathrm{~V}$ to $4 \mathrm{~V}$ per cell with an energy density of $20 \mathrm{MJ} / \mathrm{m} 3$ to 70 $\mathrm{MJ} / \mathrm{m} 3 \mathrm{can}$ be obtained.

- At present, ultra capacitors are most applicable for high peak-power, low-energy situations. Capable of floating at full charge for ten years, an ultra capacitor can provide extended power availability during voltage sags and momentary interruptions. Ultra capacitors can be completely discharged, installed easily, are compact in size, and can operate effectively in diverse (hot, cold, and moist) environments. Ultra-capacitors are now available commercially at lower power levels. A disadvantage is that a $\mathrm{SC}$ does not approach the energy density of batteries. Nevertheless, they are extremely attractive power sources.

\subsection{Compressed Air Energy Storage System (CAES :}

Power intermittency is the major problem faced by the present power sector which can be seen from lower controllability, higher variability, and lower predictability. Most important is that to cope with power intermittency, other power units have to be operated more flexibly to maintain system reliability. One additional possibility to achieve higher system flexibility is energy storage investment. Compressed air energy storage (CAES) may be an attractive investment opportunity for such purposes. Compressed Air Energy Storage (CAES) systems use off peak electrical power generated from base load plants or renewable energy sources to compress air into underground reservoir or surface vessel. More often, during the period of high electrical energy demand, the compressed air is mixed with natural gas and they are burnt together, in the same fashion as in a conventional turbine plant. This method is actually more efficient as the compressed air will lose less energy. CAES consumes two third less fuels than other conventional sources. The basic components required in a CAES plant are:

- A motor/generator which employs clutches to provide for alternate engagement to the compressor or turbine trains.

- The air compressor which may require two or more stages, intercoolers and after coolers to achieve economy of compression, and reduce the moisture content.

- The recuperator, turbine train, high and low pressure turbines.

- Equipment control centre for operating the combustion turbine, compressor.

- Auxiliaries to regulate and control changeover from generation mode to storage mode.

2.3.1 Operation: A CAES operates by means of large electric motor driven compressor that store energy in the form of compressed air in the mine. The compression is done outside periods of peak demand. As part of the compression process, the air is cooled prior to injection to make the best possible use of the storage space available. The air is then pressurised to about 75 bars.

To supply electricity to the customers, air is extracted from the cavern. It is first preheated in the recuperator. The recuperator reuses the energy extracted by the compressor coolers. The heated air is then mixed with small quantities of oil or gas, which is burnt in the combustor. The hot gas from the combustor is expanded in the turbine to generate electricity. This technology has been proven to work in solution mined salt caverns, conventionally mined hard rock caverns and aquifers. In the United States 
over $75 \%$ of its area is favourable to underground storage. The above functioning of CAES is explained by Steven (2008). The key requirement to a CAES system is that the reservoir has to be air tight and very large.

2.3.2 Performance Specification: Some of the advantages of CAES can be listed as that CAES system can be used on large scale. It has high storage capacity CAES plants take less starting time which makes it efficient from other conventional storage systems .It does not involve huge and costly installation. Also the emission of green house gases is substantially lower than in normal gas plants. The only drawback this system has is that there is actually not a lot of underground cavern around, which substantially limits the usability of this storage method. However, for locations where it is suitable, it can provide a viable option for storing energy in large quantities and for long times

\subsection{Flywheel Energy Storage System (FESS):}

A flywheel is an electromechanical device that couples a motor generator with a rotating mass to store energy for short durations. Conventional flywheels are "charged" and "discharged" via an integral motor/generator. The motor or generator draws the power from the grid which is utilized to drive the rotor of the flywheel. Kinetic energy stored in the rotor is transformed to DC electric energy by the generator, and the energy is delivered at a constant frequency and voltage through an inverter and a control system.

2.4.1 Operation: The FES devices store energy in the form of kinetic energy in the high-speed rotors. The main function of a fly wheel is to smoothen out variations in the speed of a shaft caused by torque fluctuations. Flywheel absorbs mechanical energy by increasing its angular velocity and delivers the stored energy by decreasing its velocity. In most cases, a power converter is used to drive the electric machine to provide a wider operating range. Stored energy depends on the moment of inertia of rotor and square of rotational velocity of the flywheel. Moment of inertia (J) depends on the radius, mass, and height (length) of the rotor. The rotor can be modelled as a rotating hollow cylinder. The kinetic energy $\mathrm{T}$ stored is given by

$$
T=\frac{1}{2} J \omega^{2}
$$

Where $\mathrm{J}$ is polar moment of inertia about axis of rotation and $\omega$ is the angular velocity. The energy storage capability of flywheels can be improved either by increasing the moment of inertia of flywheel or by turning it at higher rotational velocities, or both. Fig. 3 shows the flywheel electrical interface.

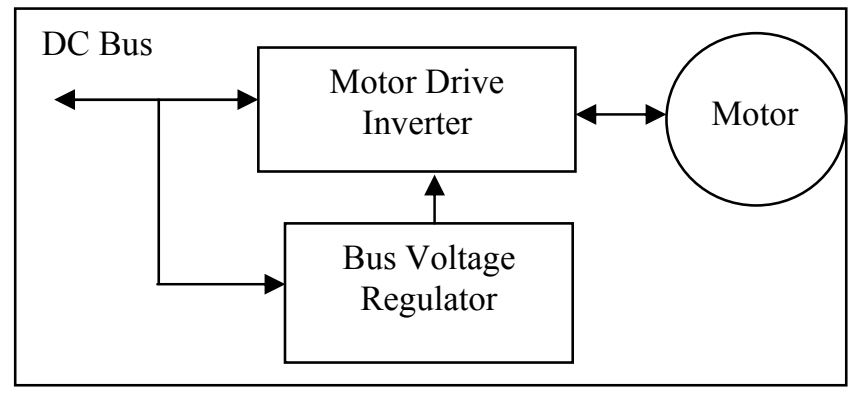

Figure 3. Flywheel Electrical Interface

2.4.2 Performance Specifications: Flywheels can respond to many power quality issues such as frequency deviation, temporary interruptions, voltage sags, and voltage swells. The amount of energy stored in an FES device mainly depends on the angular velocity of the rotor. FESS constitutes short term storage systems, which are generally sufficient to improve the power quality compared to other ways of storing electricity, FES systems have long lifetimes (ranges from in excess of $10^{5}$, up to $10^{7}$, cycles of use), high energy densities (100-130 Wh/kg, or 360-500 kJ/kg), and large maximum power outputs. Typical capacities range from $3 \mathrm{kWh}$ to $33 \mathrm{kWh}$. Rapid charging of a system occurs in less than 15 minutes. FESS has an overall round trip efficiency including the electronics, bearings, and flywheel drag of $80-85 \%$ (Sels, 2001). With the life expectancy of about 20 years, the current flywheel designs are modular and can range in size up to 10 plus MW systems. Advanced flywheels constructed from carbon fiber materials and magnetic bearings can spin in vacuum at speeds up to 40,000 to 60,000 RPM.

\subsection{Pumped Hydro Energy Storage Systems (PHESS):}

Hydroelectric storage is a process that converts electrical energy to potential energy by pumping water to a higher elevation, where it can be stored indefinitely and then released to pass through hydraulic turbines and generate electrical energy. 
2.5.1 Operation: These energy storage units require two large water reservoirs located at different heights, so that water fall is possible. During periods of low demand, the excess power is utilized to pump water from the lower reservoir and transfer it to the upper one. At peak demand periods, the pumped storage plant acts as a hydroelectric power plant thus adding capacity to the energy system shown in Figure 4.

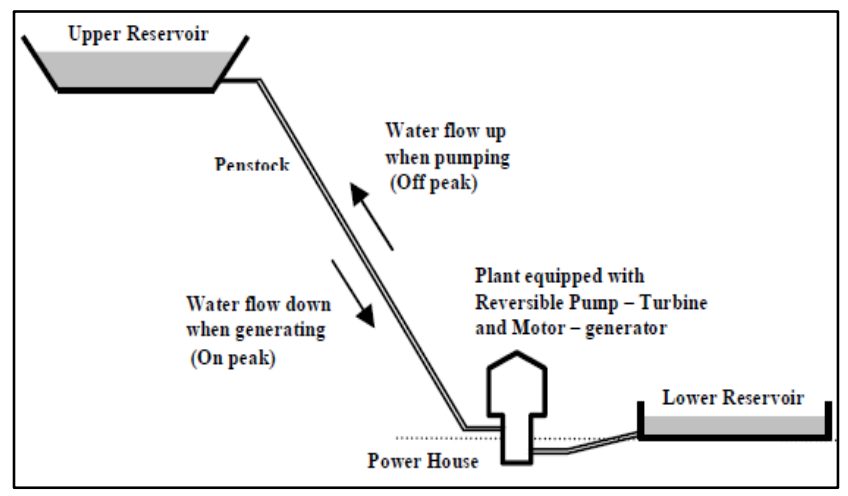

Figure 4. Schematic Diagram of PHESS

2.5.2 Performance Specification: PHESS is cost-effective if used only 5 to 8 hours in the peaking range. Its response time is of the order of 5 to 10 minutes. The above energy storage technology has been in use for over 50 years now. At present, there are about 35 pumped storage plants in operation all over the world with a total capacity of 25,000 MW. This energy storage option is most appropriate for countries with mountainous relief. Pumped storage is the most widespread energy storage system in use for utility applications. There are some 150 operational pumped-storage facilities in the United States, with a total capacity of over $25 \mathrm{GW}$ according to Steven (2008). Because of geographical, environmental, and cost constraints, construction of pumped storage facilities will be rare.

\subsection{Battery Energy Storage Systems (BESS):}

In the process of development of the new generation of BES systems, lead-acid batteries energy storage systems (LABESS) were widely used, which allowed the latter to exhibit a number of useful advantages leading to significant cost benefits. The features of lead-acid battery storage systems include Modular design, Short construction time, Small environmental impact, High level of recycling.

2.6. 1. Operation: They can be generally divided in two types: BES systems belonging to the electric power generating utilities (installed before the meter), and customer-owned BES systems. When battery storage plants are installed at the side of the electric power generating utilities, they have a power of over $1 \mathrm{MW}$. The power of lead-acid battery storage facilities (LABESF) at the customer side is of the order of 300 to $500 \mathrm{~kW}$. Schematic of Customer owned LABESS is shown in Figure 5 .Customer operated lead-acid battery storage facilities are utilized primarily for peak-shaving and load-levelling. All these applications bring immediate financial profits to the customers, and make them less dependent on the power supply utilities in peak demand periods. Thus sufficient stability of the technological processes is guaranteed. The use of lead-acid battery storage plants by electric power generating utilities is aimed not only at levelling the electric loads, but also at improving the quality of the energy delivered by the utilities to the customers. LABES systems can function as spinning reserves; provide instantaneous fast power reserve; regulate frequency, voltage damp-out, sub synchronous oscillations and other system instabilities.

ELNA America Inc. (1988) provides detailed analysis of the battery storage. For power system energy storage operation, leadacid batteries must be designed for frequent charge-discharge cycles, similar to their duty for electric vehicles. Batteries have been developed which allow 1000 to 2000 deep discharge cycles before needing replacement. Lead-acid flooded (as opposed to valve regulated) batteries, can tolerate a lower depth of discharge (to $20 \%$ of capacity) but require a regular topping-up of electrolyte. Valve-regulated (or "sealed") batteries still require some maintenance, but should not be discharged much below $50 \%$ of capacity. All constituents of lead-acid batteries can be recycled at the end of their life. 


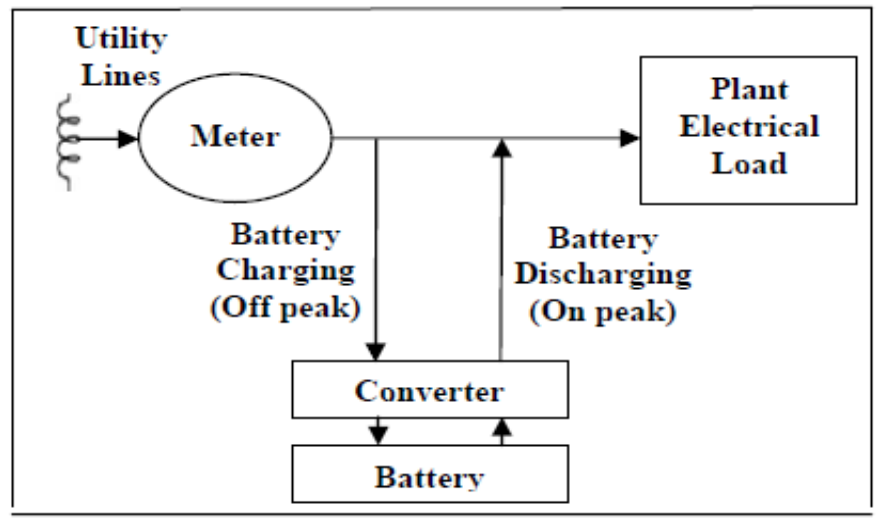

Figure 5. Schematic of a customer-owned LABESS

2.6.2 Performance Analysis: The implementation of BES systems in the power industry offers the following major benefits and advantages:

- $\quad$ Load-levelling (energy storage): Considerable cost-effective benefits are provided by utilizing low-cost energy from the base load generating utilities for meeting expensive peak energy demands.

- $\quad$ Dynamic power response - This is due to the high operating flexibility and very short response time provided by lead-acid battery plants. These plants are capable of supplying electric power for frequency control and instantaneous power reserve, and can be used for peak-shaving as well. All these functions provide dynamic power benefits resulting in improved quality of the energy delivered.

- $\quad$ Strategic advantages -These are more general in nature and have their impact on environmental protection, efficiency of power transmission and distribution networks, and economy as a whole. These benefits cannot be directly measured but can be estimated by mathematical calculation and modelling.

\section{3) Analysis of Energy Storage Devices}

On the basis of different parameters different energy storage devices have been analyzed as shown in the Table 1 .

Table1. Analysis of Energy Storage Devices

\begin{tabular}{|c|c|c|c|c|c|c|c|}
\hline S.No & Parameter & SMES & SCES & CAES & FESS & PHESS & BESS \\
\hline 1. & Typical Range & $1-100 \mathrm{MW}$ & $1-250 \mathrm{KW}$ & 25 to $350 \mathrm{MW}$ & Ranging in KW & Up to $2.1 \mathrm{GW}$ & 100-20 MW \\
\hline 2. & $\begin{array}{l}\text { Power Density } \\
(\mathrm{kW} / \mathrm{m} 3)\end{array}$ & $>530$ & $>176678$ & More than PHESS & $>707-1767$ & $\mathrm{f}\left(\mathrm{h}_{1} \sim \mathrm{h}_{2}\right)$ & $>106-7067$ \\
\hline 3. & $\begin{array}{l}\text { Energy Density } \\
\quad(\mathrm{kW}-\mathrm{h} / \mathrm{m})\end{array}$ & $>7.07$ & $>53$ & More than PHESS & $>282.7-424$ & - & $>70.7-247$ \\
\hline 4. & Emissions & No & No & No & No & No & Very Low \\
\hline 5. & $\begin{array}{l}\text { Electrical } \\
\text { Efficiency }\end{array}$ & $\sim 95 \%$ & $<95 \%$ & $\sim 70 \%$ & $90-95 \%$ & $75-80 \%$ & $88-92 \%$ \\
\hline 6. & Life time & $\sim 30$ Years & 10-20 Years & $<50$ Years & $\begin{array}{c}10-20 \mathrm{yr}(\mathrm{HS}) \\
20 \mathrm{yr}(\mathrm{LS})\end{array}$ & $\sim 50$ Years & $3-6$ yrs \\
\hline 7. & Losses/w & $17 \mathrm{~mW}$ & $0.004 \mathrm{~mW}$ & & $\begin{array}{c}6 \mathrm{~mW} \text { (LS) }-10 \mathrm{~mW} \\
\text { (high speed) }\end{array}$ & & $\begin{array}{l}0.19 \mathrm{~mW} \text { (for lead } \\
\text { acid battery) }\end{array}$ \\
\hline 8. & Frequency Regulation & No & $\begin{array}{l}\text { Needs to be } \\
\text { explored }\end{array}$ & - & Yes & - & No \\
\hline 9. & $\begin{array}{l}\text { Power Quality } \\
\text { Improvement }\end{array}$ & No & Yes & - & No & - & No \\
\hline 10. & Response Time & Milliseconds & Milliseconds & $\sim 1-2$ Mins & $\sim 1-2$ Mins & $\sim 1-2$ Mins & Seconds \\
\hline 11. & Backup Time & Seconds & Seconds & Hours & $\sim$ Mins & Days & Hours \\
\hline
\end{tabular}




\section{Conclusions}

The energy storage devices can play a very important role in the power system operation and dynamics. It ranges from transient stability enhancement by fast responding devices like SMES and SCES to peak load balancing through PHESS. The choice of a correct energy storage system depends on different parameters and requirements specified by the application. Every storage system has its own pros and cons. Among the potential performance benefits produced by advanced energy storage applications are improved system reliability, dynamic stability, enhanced power quality, transmission capacity enhancement, and area protection. By locating energy storage facilities appropriately throughout the transmission grid they can help stabilize the system by transmitting the power from the remote generation units closer to the load. The choice of which storage device should be used can be made on basis of necessary rated power, bridging time, footprint of the system, total cost, environmental conditions and restrictions, etc. The aforementioned types of the energy storage systems can be categorized into large systems used by power suppliers like energy storage by using pumped hydro, compressed air, hydrogen and flywheels, and smaller systems that can be used for industrial or residential applications like batteries and storage of the energy in the form of heat, for instance using heat pumps.

\section{References}

American Superconductor Inc., Technical Papers. Available: http://www.amsuper.comlsemsfact.thm.

Buckles W., Hassenzahl W. V. May 2000. Super conducting magnetic energy storage, IEEE Power Engineering Review, Vol. 20, No.5, pp.216-220.

Bullard G. L., Sierra-Alcazar H. B., Lee H. L., Moms J. L., January 1989. Operating principles of the Ultracapacitor, IEEE Transactions in Magnetics, Vol.25, No.1, pp.102-106.

Davidson B, Price A, Electrical energy storage - The development of a business based on REDOX FLOW batteries, in Power Gen 2000 Europe, Helsinki, CD-102.

ELNA America Inc.,1988. Comparison of double layer capacitor and batteries, Technical Paper.

European Commission, November 2000. Energy storage: A key technology for decentralized power, power quality and clean transport, in Information Day on Non-Nuclear Energy RTD, Brussels.

Hassenzahl W. V., 1997. Capacitors for electric utility energy storage: Electric Power Res. Inst., Vol. WO-8812.

Schottler R, Pailer G, Wels P, February 2000. Superconductivity against lightning strikes, Power Qualify Journal, pp.42-45.

Sels T., Dragu C., Van Craenenbroeck T. and Belmans R., 2001. New energy storage devices for an improved load managing on distribution load, IEEE Porto Power Tech Conference, pp.1- 6.

Smith S.C., Sen P.K., Benjamin K. 2008. Advancement of energy storage devices and applications in electrical power systems, IEEE PES General , pp. 1-8.

Yurek G, Howe J, Kehrli B, March 1999. Recent advances in superconductivity for electric utility T\&D systems: Laying the foundation for the electricity superhighway, Edison Electric Institute's Transmission and Distribution Spring Conference.

\section{Biographical notes}

Astha Gupta,Nitisha Nigam,\&Anubha Gupta are students in the Department of Electrical and Electronics Engineering,Krishna Institute of Engineering and Tecnology Ghaziabad, India.

Dr. N. K. Sharma (B, 86 and M, 93) got his B. Sc. (Engg.) from Faculty of Engg. Dayalbagh Educational Institute (Deemed Univ.) Agra, M.Tech. and Ph.D. from IIT Kanpur. He took voluntary retirement from MMM Engineering College Gorakhpur after 20 years of teaching \& research in the institute. Presently he is professor \& Head Electrical in RKGIT, Ghaziabad, India. He is Member Board of Studies (Electrical and Electronics), UP Technical University, Lucknow, India. He has written more than 20 research papers, supervised 5 M. Tech. and supervising 4 Ph.D.s. His area of research includes Power System Restructuring, FACTS, Network Analysis and Synthesis.

Ravi Gupta was born on March 17th, 1968 in Muzaffarnagar district of Uttar Pradesh, India. He received his B.E. (Electrical Engg.) from MMMEC, Gorakhpur and M.E. in Power Apparatus \& Electric Drives from University of Roorkee, Roorkee, since then he has been involved in teaching for the last fourteen years. He has authored more than ten papers. Currently he is working as Associate Professor in the Electrical \& Electronics Engineering Department at KIET, Ghaziabad, India. He is pursuing his PhD from JMI New Delhi as part time research scholar. Wind energy generation, power electronic converters and electric drives are his major areas of interest.

Prabhakar Tiwari was born on April 20, 1975 in Ambedkar Nagar district of Uttar Pradesh, India. He got B. E. Degree in Electrical Engineering from MMMEC, Gorakhpur and M. Tech. in Power Systems Engineering from IIT, Delhi. Since then he has been involved in teaching of various subjects of Electrical Engineering for 9 years. He has been author of one book and 11 papers. Currently he is Associate Professor in KIET, Ghaziabad, India. He is also part time research scholar in JMI, New Delhi. His major field of interest includes Power System Pricing, Stability and Network Analysis and Synthesis.

Astha Gupta is student of final year in the Department of Electrical and Electronics Engineering, Krishna Institute of Engineering and Technology Ghaziabad, India. 
Nitisha Nigam is student of final year in the Department of Electrical and Electronics Engineering, Krishna Institute of Engineering and Technology Ghaziabad, India.

Anubha Gupta is student of final year in the Department of Electrical and Electronics Engineering, Krishna Institute of Engineering and Technology Ghaziabad, India.

Received February 2011

Accepted March 2011

Final acceptance in revised form June 2011 